\title{
Consistency between Self-Reported and Recorded Values for Clinical Measures
}

\author{
Joseph Thomas III, ${ }^{1}$ Mindy Paulet, ${ }^{2}$ and Jigar R. Rajpura ${ }^{3}$ \\ ${ }^{1}$ Purdue University, College of Pharmacy and Regenstrief Center for Healthcare Engineering, Center for Health Outcomes Research \\ and Policy, Robert Heine Pharmacy Building, Room 502A, 575 Stadium Mall Drive, West Lafayette, IN 47907-2091, USA \\ ${ }^{2}$ WorkLife Programs Human Resources Purdue University, 1601 West State Street, West Lafayette, IN 47907-2091, USA \\ ${ }^{3}$ Purdue University, College of Pharmacy and Regenstrief Center for Healthcare Engineering, Center for Health Outcomes Research \\ and Policy, Robert Heine Pharmacy Building, Room 515, 575 Stadium Mall Drive, West Lafayette, IN 47907-2091, USA
}

Correspondence should be addressed to Joseph Thomas III; jt3@purdue.edu and Jigar R. Rajpura; jrajpura@purdue.edu

Received 6 October 2015; Accepted 31 December 2015

Academic Editor: Terrence D. Ruddy

Copyright (C) 2016 Joseph Thomas III et al. This is an open access article distributed under the Creative Commons Attribution License, which permits unrestricted use, distribution, and reproduction in any medium, provided the original work is properly cited.

Objectives. This study evaluated consistency between self-reported values for clinical measures and recorded clinical measures. Methods. Self-reported values were collected for the clinical measures: systolic blood pressure, diastolic blood pressure, glucose level, height, weight, and cholesterol from health risk assessments completed by enrollees in a privately insured cohort. Body mass index (BMI) was computed from reported height and weight. Practitioner recorded values for the clinical measures were obtained from health screenings. We used bivariate Pearson correlation analysis and descriptive statistics to evaluate consistency between self-reported data and recorded clinic measurements. Results. There was high correlation between self-reported clinical values and recorded clinical measures for diastolic blood pressure $(r=0.91, P=<0.0001)$, systolic blood pressure $(r=0.93, P=<0.0001)$, cholesterol ( $r=0.97, P=<0.0001)$, body mass index $(r=0.96, P=<0.0001)$, glucose $(r=0.96, P=<0.0001)$, weight $(r=0.98$, $P=<0.0001)$, and height $(r=0.89, P=<0.0001)$. Conclusions. Self-reported clinical values for each of the eight clinical measures examined had good consistency with practitioner recorded data.

\section{Introduction}

Self-reported clinical measures are inexpensive and take less time to collect [1-3] than individual clinic examinations in large study samples [4-8]. Consequently, use of selfreported clinical values collected from self-administered questionnaires as a source of information on health status is commonplace [5, 9-11].

A number of studies have examined consistency between self-reported and recorded values for clinical measures, but the studies have often been limited to a single measure [1219]. Findings from the prior studies also vary in the level of consistency reported [14, 18, 20-23]. Additional data on consistency of self-reported data with clinically recorded data would be useful in guiding use of self-reported data in research and in management of patients.
Pieper et al. [18] conducted three surveys among adults aged 25 to 74 years from 1980 to $1982(N=4086), 1985$ to $1987(N=5735)$, and 1990 to $1992(N=6305)$ in the Minneapolis-St. Paul, Minnesota, metropolitan area as part of the Minnesota Heart Survey. Participants completed a short interview in their homes, which included questions about cholesterol level, blood pressure, cigarette smoking, prescription medication use, education, and occupation. Individuals' total serum cholesterol levels were measured at the first clinic visit after completion of the interview. Among participants who provided a value for their total serum cholesterol level, the correlation between self-reported total serum cholesterol and clinically recorded total serum cholesterol ranged from 0.54 to 0.75 across all study periods.

Huang et al. [14] conducted a randomized double blind clinical trial of low-dose aspirin and vitamin $\mathrm{E}$ in primary 
prevention of cardiovascular disease and cancer in a sample of 39,876 apparently healthy women aged 45 years or older from registries of health professionals between 1993 and 1996. During enrollment, participants were asked to report their total serum cholesterol levels as a part of baseline questionnaires. Following the questionnaire, participants willing to provide a venous blood sample were mailed blood collection kits. The median time between the date of blood collection and the date of self-reported total serum cholesterol was 37 days (interquartile range, 4 to 82 days). Huang et al. reported a correlation of 0.54 between self-reported and measured total cholesterol levels. Huang et al. also reported that in general the study sample underestimated total cholesterol by $9.7 \mathrm{mg} / \mathrm{dL}$.

Body mass index (BMI) is often used as an indicator of overweight and obesity and obesity has been identified as an important risk factor for many diseases, including cardiovascular disease and diabetes [24, 25]. Since BMI is computed based on height and weight, a number of studies have examined consistency between self-reported height and weight with recorded values and how differences affect estimated BMI values.

Fonseca et al. [21] recruited 462 students in grades 6, 8, and 10 from 12 Portuguese public schools to assess accuracy of adolescent's reported weight and height in comparison with recorded weight and height. All students were asked to answer a one-sheet anonymous questionnaire in which they reported their weight and height. Investigators computed student's body mass index (BMI) from the self-reported height and weight. After students completed the survey, height and weight of students were measured and BMI computed based on the measurements. Fonseca et al. found high correlation between reported and recorded weight (0.84) and between reported and recorded height (0.96). Among girls, self-report based BMI and measurement based BMI were highly correlated, with reported BMI explaining approximately $79 \%\left(R^{2}=\right.$ 0.785) of the variance in measured BMI, with a standard error of approximately $1.6 \mathrm{~kg} / \mathrm{m}^{2}$. Among boys, computed BMI (from self-reported height and weight) explained $65 \%$ $\left(R^{2}=0.651\right)$ of the variance in measurement based BMI, with a standard error of $2.1 \mathrm{~kg} / \mathrm{m}^{2}$.

Niedhammer et al. [23] studied 20,624 men aged 40 to 50 years and women aged 35 to 50 years, working in a French national company in 2000 to examine accuracy of self-reported weight and height and resulting body mass index (BMI) in comparison with clinically measured BMI. Self-reported weight and height of individuals in the study cohort were collected in an annual medical questionnaire. Recorded clinical measures were obtained from a followup annual medical examination in the same year. For each subject, physician measured height and weight data were matched with self-reported data from the self-administered questionnaire nearest in time.

Subjects were excluded from the analysis if the interval between the measured and self-reported data was longer than 6 months. Correlation between self-reported and measured weight was 0.98 and correlation between self-reported and measured height was 0.98 . Correlation between self-report based BMI and BMI based on recorded measures was 0.97. The mean difference between measured and self-reported weight was greater for women $(0.85 \mathrm{~kg})$ than men $(0.54 \mathrm{~kg})$ and there was a greater mean difference between measured and self-reported BMI for women $\left(0.44 \mathrm{~kg} / \mathrm{m}^{2}\right)$ than men $\left(0.29 \mathrm{~kg} / \mathrm{m}^{2}\right)$.

McAdams et al. [22] analyzed data from National Health and Nutrition Education Study III participants 20 years old or older to examine accuracy of self-reported weight and height and the resulting body mass index (BMI) in comparison with clinically measured BMI. Investigators collected selfreported information from a home based self-administered questionnaire. That was followed by a home based clinical examination conducted by trained health technicians.

Average time interval between collection of reported data and the clinical examination was 33.5 days. McAdams found study participants under reported weight by $0.56 \mathrm{~kg}$ and height by $0.76 \mathrm{~cm}$. Subsequently self-reported BMI $\left(25.07 \mathrm{~kg} / \mathrm{m}^{2}\right)$ was lower than measured BMI $\left(25.52 \mathrm{~kg} / \mathrm{m}^{2}\right)$. However, the correlations between self-reported and measured BMI values were high (0.95 for whites, 0.93 for blacks, and 0.90 for Mexican Americans).

Brener et al. [20] recruited 4619 students in grades 9 to 12. Students completed questionnaires to report their height and weight. Following completion of self-administered questionnaires, students' height and weight were measured and recorded. Average time between collection of student reported data and the clinical examinations was 3 days. Brener reported strong overall correlations between selfreported height (0.90), weight (0.93), and BMI (0.89) with their measured values. Students tended to overreport their height by 2.7 inches and to underreport their weight by 3.5 pounds. Consequently, self-reported BMI values were an average of $2.6 \mathrm{~kg} / \mathrm{m}^{2}$ lower than BMI based on recorded values.

We found no studies that assessed consistency of selfreported blood glucose level or self-reported blood pressure measures with recorded clinical measures.

The objective of this study was to evaluate concordance between self-reported blood pressure, cholesterol, blood glucose, height, weight, and BMI with recorded clinical measures.

\section{Methods}

2.1. Sample Selection. The cross-sectional study sample consisted of individuals 18 years or older as of January 2006 who were enrolled in a privately insured cohort employed by a large state university. Individuals eligible for participation included all covered employees who were hired on or before December 1 of the year prior to each health risk assessment. Participation was limited to faculty or staff classified as "benefit eligible," that is, those who were employed half-time or more and their spouses or same sex domestic partners, and was voluntary. Individuals who had completed health risk assessments were eligible for inclusion in the study sample. Recorded clinical measures were obtained from health care screening prior to or subsequent to completion of health 
risk assessments. The project was reviewed and approved by the Purdue University Institutional Review Board, West Lafayette, Indiana.

2.2. Data Sources and Study Variables. Data on self-reported clinical measures were taken from health risk assessment surveys completed by privately insured employees of a state university. Data on clinically recorded values for the clinical measures were taken from data recorded during health screenings. The self-reported data and the clinically recorded data included variables for systolic blood pressure, diastolic blood pressure, blood cholesterol, blood glucose, weight in pounds, and height in inches. BMI values were computed from individual's reported height and weight measures and from clinically recorded height and weight. Information on demographic variables, including age, gender, staff type, income, and whether the person completing the assessment was an employee or spouse covered under the employee's insurance plan, was obtained from plan enrollment files and was based on January of 2006 or the earliest enrollment month for each individual during that year.

To include only plausible clinical values ranges were established for each clinical measure at which values below or above the specified range were excluded from the analysis. The intervals established for each clinical measure were systolic and diastolic BP was between $40 \mathrm{~mm} / \mathrm{Hg}$ and $250 \mathrm{~mm} / \mathrm{Hg}$, total serum cholesterol levels between $75 \mathrm{mg} / \mathrm{dL}$ and $500 \mathrm{mg} / \mathrm{dL}$, body mass index between $10 \mathrm{~kg} / \mathrm{m}^{2}$ and $100 \mathrm{~kg} / \mathrm{m}^{2}$, serum glucose levels between $10 \mathrm{mg} / \mathrm{dL}$ and $500 \mathrm{mg} / \mathrm{dL}$, weight between $60 \mathrm{lbs}$ and $700 \mathrm{lbs}$, and height between 36 and 86 inches.

2.3. Statistical Analysis. The study sample was categorized based on demographic characteristics including age, gender, staff type, employee/spouse, and income. Pearson's correlation analysis was used to assess consistency between selfreported clinical values and recorded clinic measurements. Mean differences, standard deviations, and absolute differences between self-reported and recorded clinic measures were calculated. All analyses were conducted using SAS version 9.1 (SAS Institute, Cary, NC, USA) with 0.05 alpha level.

\section{Results}

As shown in Table 1 a total of 12,752 respondents met sample inclusion criteria of being at least 18 years of age. Out of those, 3630 respondents with a clinical examination within \pm 90 days of their Health risk assessment were selected for further analyses. More than half (58.8\%) of the sample was female. Only a small number values had to be excluded for being outside the established range for a measure. The highest number for any value was 21 values, and most, 16 , of those were recorded values that were excluded. None of the recorded or self-reported diastolic blood pressure had to be excluded for being above or below the established range. One recorded systolic blood pressure value was excluded for being below the established range and no self-reported systolic blood pressures were excluded for being above or below the established range. Two recorded cholesterol values were excluded for being below the established range but none of the self-reported cholesterol values had to be excluded for being outside the range. For recorded glucose, values were excluded for being below the range while six self-reported glucose values were excluded for being outside the established range, five for being below the range and one for being over the range. Three recorded weight values were excluded for being below the range and no self-reported weight values were outside the range. A total of 16 height values were excluded for being outside the range, seven for being below the range, and nine for being over the range. Only five selfreported height values were excluded for being outside the range and all five were above the range.

Table 2 shows mean differences between self-reported values and recorded clinical measures and correlations between self-reported clinical values and recorded clinic measures for diastolic blood pressure, systolic blood pressure, cholesterol, BMI, glucose, weight, and height. Absolute mean differences were also examined since values above and below the recorded values might tend to cancel each other out in mean differences. As seen in Table 2, the mean differences self-reported and recorded values were low. The mean absolute differences between the values were also low. Correlations were high and ranged from 0.89 for height to 0.98 for weight.

In assessing differences between female and male respondents in Table 3 with respect to reporting accuracy across clinical measures only weight, height, and BMI were observed to differ significantly in level of consistency across gender. Males were observed to overreport their weight by $2.26 \mathrm{lbs}$ and females by $1.02 \mathrm{lbs}$. Subsequently BMI was overreported across both gender groups. In Table 4, absolute difference between self-reported weight and recorded weight measure was observed to be 2.12 pounds for females and 3.19 pounds for males.

\section{Discussion}

Prior studies of consistency between self-reported clinical measures and recorded values have often been limited to single clinical measures or subgroups. We found no studies that evaluated concordance between self-reported blood pressure or self-reported blood glucose levels with prior clinically measured data.

Similar to the findings in studies conducted by Pieper et al. [18], Niedhammer et al. [23], McAdams et al. [22], Brener et al. [20], Huang et al. [14], Newell et al. [2], and Harlow and Linet [5] in large representative cohorts, we observed that self-reported clinical values are consistent with recorded clinic measures. Also, similar to results observed by Pieper et al. [18], Huang et al. [14], Niedhammer et al. [23], McAdams et al. [22], and Brener et al. [20], we found strong positive correlations and low differences between reported and recorded clinic measures. In Huang et al's [14] study on accuracy of self-reported cholesterol in women, $37.8 \%$ of the study sample overreported their cholesterol [14]. Similarly, in our study, respondents overreported their 
TABle 1: Sample Distribution by Demographic Characteristics.

\begin{tabular}{|c|c|c|c|c|c|c|c|}
\hline \multirow[t]{2}{*}{ Characteristics } & \multicolumn{2}{|c|}{$\begin{array}{c}\text { Total } \\
N=12,752\end{array}$} & \multicolumn{2}{|c|}{$\begin{array}{l}\text { Individuals with health risk assessment } \\
\text { and no health screen within } 90 \text { days of } \\
\text { risk assessment } \\
\qquad N=9,122\end{array}$} & \multicolumn{2}{|c|}{$\begin{array}{l}\text { Individuals with health risk assessment } \\
\text { and a health screen within } 90 \text { days of } \\
\text { risk assessment } \\
\qquad N=3,630\end{array}$} & \multirow[t]{2}{*}{$P$ value } \\
\hline & Number & $\%$ & Number & $\%$ & Number & $\%$ & \\
\hline \multicolumn{8}{|l|}{ Age } \\
\hline Less than 30 & 1,274 & 9.9 & 865 & 9.4 & 409 & 11.2 & \multirow{5}{*}{$<0.001$} \\
\hline 30 to 39 & 2,771 & 21.7 & 1,939 & 21.2 & 832 & 22.9 & \\
\hline 40 to 49 & 3,285 & 25.7 & 2,305 & 25.2 & 980 & 26.9 & \\
\hline 50 to 59 & 3,795 & 29.7 & 2,750 & 30.1 & 1,045 & 28.7 & \\
\hline 60 to 69 & 1,481 & 11.6 & 1,134 & 12.4 & 347 & 9.5 & \\
\hline \multicolumn{8}{|l|}{ Gender } \\
\hline Female & 7,306 & 57.2 & 5,171 & 56.6 & 2,135 & 58.5 & \multirow{2}{*}{0.028} \\
\hline Male & 5,446 & 42.7 & 3,951 & 43.3 & 1,495 & 41.8 & \\
\hline \multicolumn{8}{|l|}{ Staff type } \\
\hline Administrative & 4,662 & 36.5 & 3,189 & 34.9 & 1,473 & 40.5 & \multirow{5}{*}{$<0.001$} \\
\hline Clerical & 2,121 & 16.6 & 1,541 & 16.9 & 580 & 15.9 & \\
\hline Faculty & 2,807 & 22.0 & 2,286 & 25.0 & 521 & 14.3 & \\
\hline Operations & 682 & 5.3 & 497 & 5.4 & 185 & 5.1 & \\
\hline Service & 2,479 & 19.4 & 1,608 & 17.6 & 871 & 23.9 & \\
\hline \multicolumn{8}{|l|}{ Employee/spouse } \\
\hline Employee & 9,645 & 75.6 & 6,105 & 65.9 & 3,630 & 100.0 & \multirow{2}{*}{$<0.001$} \\
\hline Spouse & 3,106 & 24.3 & 3,106 & 34.0 & 0 & 0 & \\
\hline \multicolumn{8}{|l|}{ Income } \\
\hline Less than $\$ 30,000$ & 4,479 & 35.1 & 3,278 & 35.9 & 1,201 & 33.0 & \multirow{7}{*}{$<0.001$} \\
\hline$\$ 30,000$ to $\$ 60,000$ & 5,374 & 41.9 & 3,608 & 39.5 & 1,325 & 47.9 & \\
\hline$\$ 60,000$ to $\$ 90,000$ & 1,784 & 13.9 & 1,349 & 14.7 & 435 & 13.9 & \\
\hline$\$ 90,000$ to $\$ 120,000$ & 718 & 5.6 & 559 & 6.1 & 159 & 4.3 & \\
\hline$\$ 120,000$ to $\$ 150,000$ & 47 & 0.2 & 37 & 0.4 & 10 & 0.2 & \\
\hline$\$ 150,000$ to 180,000 & 102 & 0.8 & 80 & 0.8 & 22 & 0.6 & \\
\hline More than $\$ 180,000$ & 63 & 0.4 & 50 & 0.5 & 13 & 0.3 & \\
\hline
\end{tabular}

TABLE 2: Mean differences between self-reported values and recorded values on clinical measures.

\begin{tabular}{lccccccccc}
\hline $\begin{array}{l}\text { Clinical } \\
\text { measures }\end{array}$ & Number & $\begin{array}{c}\text { Mean } \\
\text { difference }\end{array}$ & $\begin{array}{c}\text { Standard } \\
\text { deviation }\end{array}$ & $P$ value & $\begin{array}{c}\text { Absolute } \\
\text { difference }\end{array}$ & $\begin{array}{c}\text { Standard } \\
\text { deviation }\end{array}$ & $P$ value ${ }^{1}$ & $P^{\text {Pearson corr. }}$ & $P$ value \\
\hline Diastolic BP & 3,612 & 0.86 & 4.10 & $<0.001$ & 1.63 & 3.86 & $<0.001$ & 0.91 & $<0.001$ \\
Systolic BP & 3,611 & 0.99 & 4.86 & $<0.001$ & 1.82 & 4.62 & $<0.001$ & 0.93 & $<0.001$ \\
Cholesterol & 3,597 & 0.10 & 10.58 & 0.576 & 1.54 & 10.47 & $<0.001$ & 0.97 & $<0.001$ \\
BMI & 3,357 & 0.71 & 1.80 & $<0.001$ & 1.05 & 1.63 & $<0.001$ & 0.96 & $<0.001$ \\
Glucose & 3,590 & 0.39 & 8.66 & 0.007 & 1.31 & 8.57 & $<0.001$ & 0.96 & $<0.001$ \\
Weight & 3,607 & 1.53 & 8.44 & $<0.001$ & 2.56 & 8.18 & $<0.001$ & 0.98 & $<0.001$ \\
Height & 3,593 & 0.03 & 1.93 & 0.382 & 0.76 & 1.78 & $<0.001$ & 0.89 & $<0.001$ \\
\hline
\end{tabular}

${ }^{1} P$ values from paired $t$-test between values from self-reported and recorded clinical measures. 
TABLE 3: Comparison of difference between male and female participants' self-reported values and recorded values on clinical measures.

\begin{tabular}{|c|c|c|c|c|c|c|c|}
\hline \multirow{2}{*}{ Clinical measures } & \multirow{2}{*}{ Number } & \multicolumn{2}{|c|}{ Females } & \multirow{2}{*}{ Number } & \multicolumn{2}{|c|}{ Males } & \multirow{2}{*}{$P$ value ${ }^{1}$} \\
\hline & & Mean difference & Standard deviation & & Mean difference & Standard deviation & \\
\hline Diastolic BP & 2,123 & 0.83 & 4.02 & 1,488 & 0.90 & 4.22 & 0.630 \\
\hline Systolic BP & 2,122 & 0.96 & 4.73 & 1,488 & 1.02 & 5.04 & 0.720 \\
\hline Cholesterol & 2,121 & -0.04 & 11.08 & 1,475 & 0.30 & 9.82 & 0.328 \\
\hline BMI & 1,999 & 0.61 & 1.69 & 1,357 & 0.85 & 1.95 & 0.002 \\
\hline Glucose & 2,117 & 0.35 & 8.54 & 1,472 & 0.44 & 8.83 & 0.774 \\
\hline Weight & 2,119 & 1.02 & 7.88 & 1,487 & 2.26 & 9.12 & $<0.001$ \\
\hline Height & 2,115 & 0.08 & 1.87 & 1,477 & -0.05 & 2.01 & 0.039 \\
\hline
\end{tabular}

${ }^{1} P$ values from $t$-test comparing mean differences in self-reported and recorded clinical measures between male and female participants.

TABLE 4: Comparison of absolute difference between male and female participants' self-reported values and recorded values on clinical measures.

\begin{tabular}{|c|c|c|c|c|c|c|c|}
\hline \multirow{2}{*}{ Clinical measures } & \multirow{2}{*}{ Number } & \multicolumn{2}{|c|}{ Females } & \multirow{2}{*}{ Number } & \multicolumn{2}{|c|}{ Males } & \multirow{2}{*}{$P$ value ${ }^{1}$} \\
\hline & & Mean difference & Standard deviation & & Mean difference & Standard deviation & \\
\hline Diastolic BP & 2,123 & 1.54 & 3.81 & 1,488 & 1.75 & 3.94 & 0.103 \\
\hline Systolic BP & 2,122 & 1.73 & 4.51 & 1,488 & 1.93 & 4.77 & 0.205 \\
\hline Cholesterol & 2,121 & 1.54 & 10.97 & 1,475 & 1.54 & 9.71 & 0.989 \\
\hline BMI & 1,999 & 1.00 & 1.49 & 1,357 & 1.13 & 1.80 & 0.021 \\
\hline Glucose & 2,117 & 1.23 & 8.45 & 1,472 & 1.41 & 8.73 & 0.552 \\
\hline Weight & 2,119 & 2.12 & 7.66 & 1,487 & 3.19 & 8.84 & 0.002 \\
\hline Height & 2,115 & 0.75 & 1.72 & 1,477 & 0.76 & 1.86 & 0.800 \\
\hline
\end{tabular}

${ }^{1} P$ values from $t$-test comparing mean differences in self-reported and recorded clinical measures between male and female participants.

cholesterol on average by only $0.10 \mathrm{mg} / \mathrm{dL}$, which is of little clinical significance. These findings collectively suggest that information collected through administered health survey in our privately insured health cohort is accurate.

Limitations. The study sample consisted of individuals only from a small geographical region and a specific private cohort that require caution in generalizing the findings.

\section{Conclusion}

In conclusion, self-reported clinical values could be reliable in cohort based epidemiologic studies for blood pressure, cholesterol, glucose, BMI, and weight measures in a private insurance-based cohort. Self-administered health survey continues to be important tools in epidemiology research.

\section{Conflict of Interests}

The authors are employees of the organization that provided data for the analysis and one author was manager of the program that collected the data used in the analysis.

\section{Acknowledgments}

The authors would like to express their appreciation to Zhiyi Tian for statistical analysis support. This work was supported partially by the Purdue University, Regenstrief Center for Healthcare Engineering. The sponsor had no involvement in the study design, collection, analysis, or interpretation of data, writing of the report, or decision to submit the paper for publication.

\section{References}

[1] E. A. Molenaar, E. J. C. V. Ameijden, D. E. Grobbee, and M. E. Numans, "Comparison of routine care self-reported and biometrical data on hypertension and diabetes: results of the Utrecht Health Project," The European Journal of Public Health, vol. 17, no. 2, pp. 199-205, 2006.

[2] S. A. Newell, A. Girgis, R. W. Sanson-Fisher, and N. J. Savolainen, "The accuracy of self-reported health behaviors and risk factors relating to cancer and cardiovascular disease in the general population," American Journal of Preventive Medicine, vol. 17, no. 3, pp. 211-229, 1999.

[3] C. D. Sherbourne and L. S. Meredith, "Quality of self-report data: a comparison of older and younger chronically ill patients," Journals of Gerontology, vol. 47, no. 4, pp. S204-S211, 1992.

[4] G. Chatellier, C. Dutrey-Dupagne, L. Vaur et al., "Home self blood pressure measurement in general practice: the SMART study," American Journal of Hypertension, vol. 9, no. 7, pp. 644652, 1996.

[5] S. D. Harlow and M. S. Linet, "Agreement between questionnaire data and medical records. The evidence for accuracy of recall," American Journal of Epidemiology, vol. 129, no. 2, pp. 233-248, 1989.

[6] S. Julius, "Home blood pressure monitoring: advantages and limitations," Journal of Hypertension. Supplement, vol. 9, no. 3, pp. S41-S46, 1991. 
[7] D. E. Krueger, "Measurement of prevalence of chronic disease by household interviews and clinical evaluations," American Journal of Public Health and the Nations Health, vol. 47, no. 8, pp. 953-960, 1957.

[8] J. W. Meltzer and J. R. Hochstim, "Reliability and validity of survey data on physical health," Public Health Reports, vol. 85, no. 12, pp. 1075-1086, 1970.

[9] T. L. Bush, S. R. Miller, A. L. Golden, and W. E. Hale, "Selfreport and medical record report agreement of selected medical conditions in the elderly," American Journal of Public Health, vol. 79, no. 11, pp. 1554-1556, 1989.

[10] K. Midthjell, J. Holmen, A. Bjorndal, and P. G. Lund-Larsen, "Is questionnaire information valid in the study of a chronic disease such as diabetes? The Nord-Trondelag diabetes study," Journal of Epidemiology and Community Health, vol. 46, no. 5, pp. 537-542, 1992.

[11] S. Tretli, P. G. Lund-Larsen, and O. P. Foss, "Reliability of questionnaire information on cardiovascular disease and diabetes: cardiovascular disease study in Finnmark county," Journal of Epidemiology and Community Health, vol. 36, no. 4, pp. 269273, 1982.

[12] C. Cheng, J. S. Studdiford, V. Chambers, J. J. Diamond, and N. Paynter, "The reliability of patient self-reported blood pressures," Journal of Clinical Hypertension, vol. 4, no. 4, pp. 259273, 2002.

[13] L. A. Gonder-Frederick, D. M. Julian, D. J. Cox, W. L. Clarke, and W. R. Carter, "Self-measurement of blood glucose. Accuracy of self-reported data and adherence to recommended regimen," Diabetes Care, vol. 11, no. 7, pp. 579-585, 1988.

[14] P.-Y. A. Huang, J. E. Buring, P. M. Ridker, and R. J. Glynn, "Awareness, accuracy, and predictive validity of self-reported cholesterol in women," Journal of General Internal Medicine, vol. 22, no. 5, pp. 606-613, 2007.

[15] K. A. Johnson, D. J. Partsch, L. L. Rippole, and D. M. McVey, "Reliability of self-reported blood pressure measurements," Archives of Internal Medicine, vol. 159, no. 22, pp. 2689-2693, 1999.

[16] R. S. Mazze, H. Shamoon, R. Pasmantier et al., "Reliability of blood glucose monitoring by patients with diabetes mellitus," The American Journal of Medicine, vol. 77, no. 2, pp. 211-217, 1984.

[17] I. S. Nash, L. Mosca, R. S. Blumenthal, M. H. Davidson, S. C. Smith Jr., and R. C. Pasternak, "Contemporary awareness and understanding of cholesterol as a risk factor: results of an American Heart Association National Survey," Archives of Internal Medicine, vol. 163, no. 13, pp. 1597-1600, 2003.

[18] R. M. Pieper, D. K. Arnett, P. G. McGovern, E. Shahar, H. Blackburn, and R. V. Luepker, "Trends in cholesterol knowledge and screening and hypercholesterolemia awareness and treatment, 1980-1992: the Minnesota Heart Survey," Archives of Internal Medicine, vol. 157, no. 20, pp. 2326-2332, 1997.

[19] O. Ziegler, M. Kolopp, I. Got, P. Genton, G. Debry, and P. Drouin, "Reliability of self-monitoring of blood glucose by CSII-treated patients with type I diabetes," Diabetes Care, vol. 12, no. 3, pp. 184-188, 1989.

[20] N. D. Brener, T. McManus, D. A. Galuska, R. Lowry, and $\mathrm{H}$. Wechsler, "Reliability and validity of self-reported height and weight among high school students," Journal of Adolescent Health, vol. 32, no. 4, pp. 281-287, 2003.

[21] H. Fonseca, A. M. Silva, M. G. Matos et al., "Validity of BMI based on self-reported weight and height in adolescents," Acta
Paediatrica, International Journal of Paediatrics, vol. 99, no. 1, pp. 83-88, 2010.

[22] M. A. McAdams, R. M. Van Dam, and F. B. Hu, "Comparison of self-reported and measured BMI as correlates of disease markers in U.S. adults," Obesity, vol. 15, no. 1, pp. 188-196, 2007.

[23] I. Niedhammer, I. Bugel, S. Bonenfant, M. Goldberg, and A. Leclerc, "Validity of self-reported weight and height in the french GAZEL cohort," International Journal of Obesity, vol. 24, no. 9, pp. 1111-1118, 2000.

[24] G. A. Bray, "Overweight is risking fate. Definition, classification, prevalence, and risks," Annals of the New York Academy of Sciences, vol. 499, pp. 14-28, 1987.

[25] F. X. Pi-Sunyer, "Medical hazards of obesity," Annals of Internal Medicine, vol. 119, no. 7, part 2, pp. 655-660, 1993. 


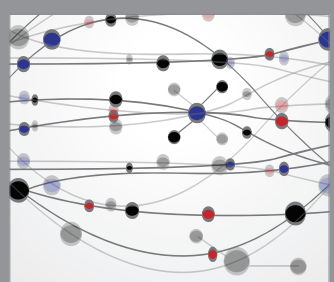

The Scientific World Journal
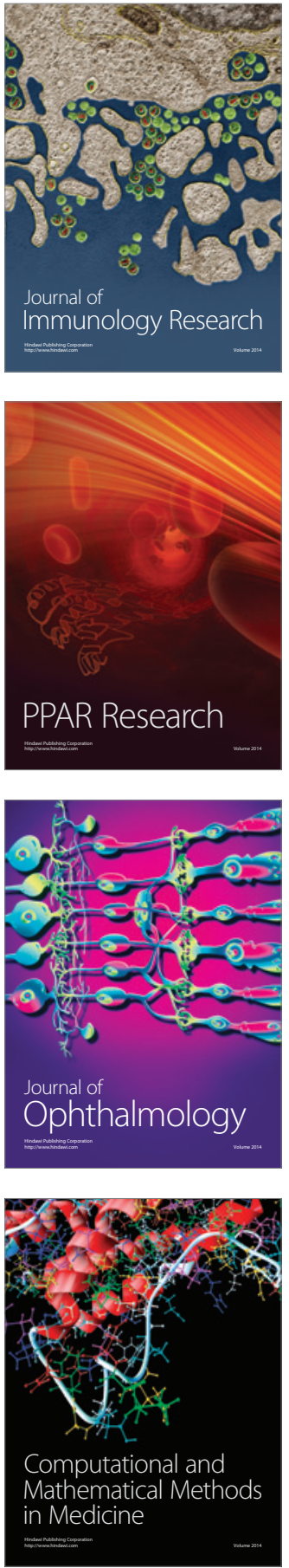

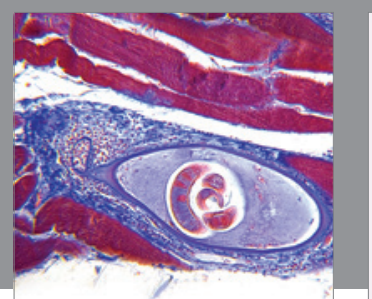

Gastroenterology Research and Practice

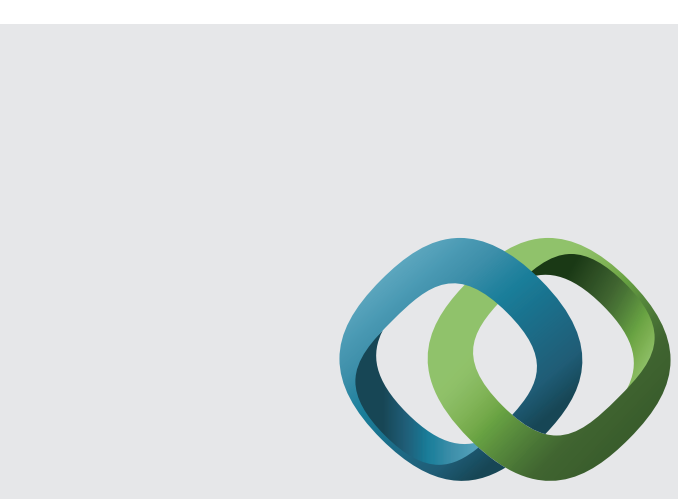

\section{Hindawi}

Submit your manuscripts at

http://www.hindawi.com
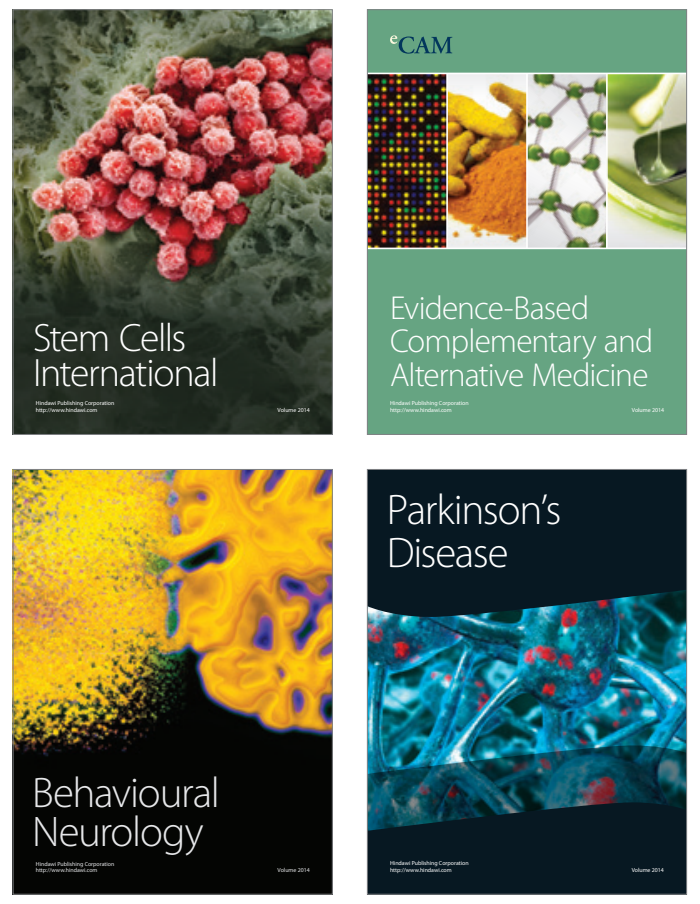
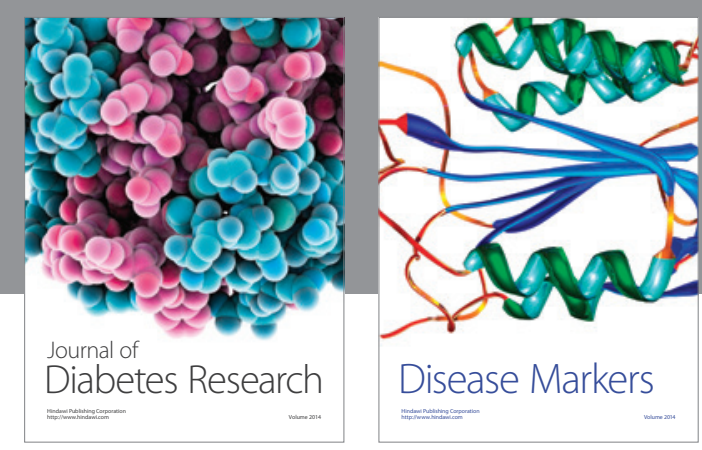

Disease Markers
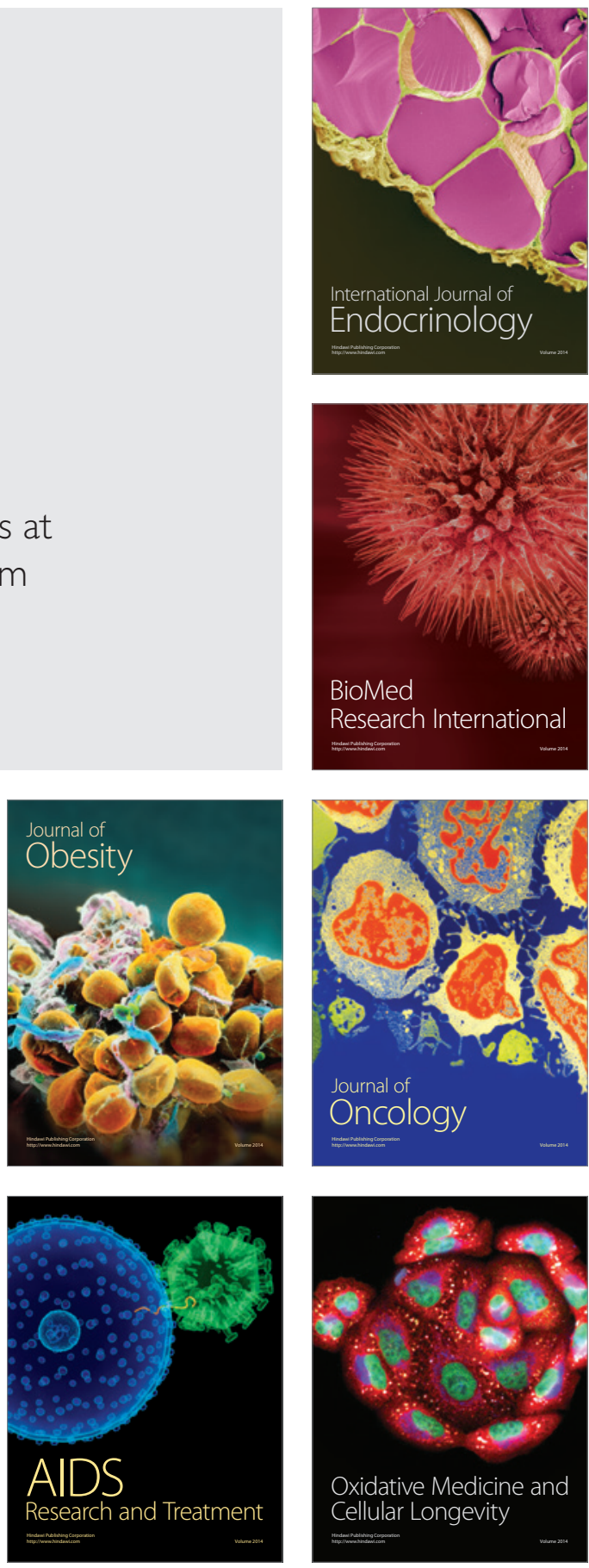